Article

\title{
Novel Ergot Alkaloids Production from Penicillium citrinum Employing Response Surface Methodology Technique
}

\author{
Memuna Ghafoor Shahid 1,*(D), Muhammad Nadeem ${ }^{2}$, Ahmed Gulzar ${ }^{3}$, Muhammad Saleem ${ }^{4}$, \\ Hafeez ur Rehman ${ }^{3}$, Gul Zareen Ghafoor ${ }^{5}{ }^{(}$, Muhammad Umar Hayyat $^{5}$, Laila Shahzad ${ }^{5}$, \\ Rabia Arif ${ }^{4}$ and Rubina Nelofer ${ }^{2}$ (D) \\ 1 Department of Botany, GC University, Lahore 54000, Pakistan \\ 2 Food and Biotechnology Research Center, PCSIR Laboratories Complex, Lahore 54000, Pakistan; \\ mnadeempk@yahoo.com (M.N.); rubinanelofer@gmail.com (R.N.) \\ 3 Department of Economics, University of Management \& Technology, Lahore 54000, Pakistan; \\ ahmedgulzar2011@gmail.com (A.G.); hafeez.rehman@umt.edu.pk (H.u.R.) \\ 4 Department of Botany, University of the Punjab, New Campus, Lahore 54000, Pakistan; \\ saleem.botany@pu.edu.pk (M.S.); phdgenetics@gmail.com (R.A.) \\ 5 Sustainable Development Study Center, GC University, Lahore 54000, Pakistan; \\ zareen.sdsc@gmail.com (G.Z.G.); umerenv@yahoo.com (M.U.H.); lailashahzad@gcu.edu.pk (L.S.) \\ * Correspondence: memunaghafoorshahid@gmail.com
}

Received: 7 April 2020; Accepted: 30 May 2020; Published: 29 June 2020

\begin{abstract}
Ergot alkaloids are novel pharmaceutical and therapeutic agents synthesized in this study using fungal species Penicillium citrinum. To get the maximum yield of ergot alkaloids a statistical process of response surface methodology was employed using surface culture fermentation technique. Initially, the strain of Penicillium was improved using physical (ultraviolet (UV) and chemical (ethyl methane sulfonate (EMS) treatments to get the maximum yield of ergot alkaloids through surface culture fermentation technique. After improving the strain, survival rate of colonies of Penicillium citrinum treated with UV and EMS was observed. Only 2.04\% living colonies were observed after 150 min of exposure of Penicillium citrinum in UV light and 3.2\% living colonies were observed after 20 min of the exposure in EMS. The mutated strains of Penicillium citrinum were screened for their production of ergot alkaloids and after fermentation experiments, maximum yield was obtained from PCUV-4 and PCEMS-1 strains. After strain improvement, Plackett-Burman design (PBD) and Box-Behnken design (BBD) of RSM were employed and 10-fold yield enhancement $(35.60 \mathrm{mg} / 100 \mathrm{~mL})$ of ergot alkaloids was achieved. This enhancement in yield of ergot alkaloids proved the positive impacts of RSM and UV on the yield of ergot alkaloids. The study provides a cost effective, economical and sustainable process to produce medically important ergot alkaloids which can be used in various pharmaceutical formulations to treat human diseases.
\end{abstract}

Keywords: ergot alkaloids; strain improvement; UV; EMS; Penicillium citrinum; response surface methodology; PBD; BBD

Key Contribution: The production of pharmaceutically and therapeutically important alkaloids using cost effective and sustainable technique can uplift the economy of a country.

\section{Introduction}

Secondary metabolites are organic compounds produced by different species of bacteria, fungi and plants that are helpful in their growth, development and reproduction. They play a supportive role in the 
long-term impairment of an organism's health, survival and formation of the offspring. The secondary metabolites are sometimes restricted to a specific set of species within a group of organisms. These are also helpful in the plant defense mechanism against insects and other organisms and can be used by human beings in various industrial, pharmacological and commercial applications [1]. Natural products or secondary metabolites are also known as bioactive compounds which are helping in the discovery and manufacturing of various drugs for the treatment of human ailments [2]. Many plant, animal and fungal species are known for producing naturally occurring bioactive compounds called alkaloids which are considered as a major group of naturally synthesized secondary metabolites [3].

Ergot alkaloids are being described as an assemblage of bioactive compounds of various species including plants and fungi. These were initially documented in Claviceps purpurea (a fungal species), the agent known for causing the disease of ergot of rye. These ergot alkaloids were the first time isolated and identified in the sclerotia produced on the kernels of rye plant. Many types of commercially and industrially significant ergot alkaloids were reported from the sclerotia of genus Claviceps. However, other species of fungi such as Blansia, Epichole, Penicillium and Aspergillus and several higher plants can also produce some quantity of ergot alkaloids [4]. In fungi, ascomycetes can efficiently produce alkaloids naturally and in laboratories. Penicillium, a well-known genus of Ascomycetes is significant for producing commercially valued secondary metabolites [5,6]. Penicillium species can produce significant amounts of alkaloids, antibiotics, hormones and mycotoxins [7]. Ergot alkaloids have been divided into three types on the basis of their structures such as clavines, lysergic acid amides and ergopeptines [8]. Ergot alkaloids are produced commercially for manufacturing of drugs employing various fermentation techniques. Alkaloids synthesis was regulated and enhanced industrially by adding different organic and inorganic ingredients in fermentation medium [3].

The yield of any product can also be enhanced by employing some statistical optimization parameters which help in the quick screening and selection of a number of fermentation factors/ingredients at one time to get the maximum yield of the product in fermentation medium. These statistical procedures also reflect the role and interaction of every individual factor in a specific fermentation method. response surface methodology (RSM) is composed of mathematical and statistical techniques for developing the empirical modeling of a fermentation process for optimizing conditions for producing industrially and commercially important secondary metabolites [9]. Methods and techniques in the synthesis of ergot alkaloids were improved over time with advancement of techniques and still efforts are being conceded, using the optimization techniques of fermentation technology, genetic improvement of strain and the use of protoplasts of the cultures [10].

Statistical designs such as Plackett-Burman design (PBD) [11] and Box-Behnken design (BBD) [12] are very effective and significant techniques for the investigation of targeted factors of fermentation medium. PBD is an efficient screening approach that reduces the number of experiments and gives information for the evaluation of target factors. Only the significant factors with positive responses are selected for further optimization [11,13]. In contrast, BBD is used to generate higher order responses using fewer experimental runs than a normal one factor at a time technique. The Box-Behnken design uses the twelve middle-edge nodes and three center-nodes to fit a 2nd order equation. Box-Behnken designs place points on the mid points of the edges of the cubical design region, as well as points at the center [14]. Another significance of the BBD is that it does not contain combinations for which all factors are simultaneously at their highest or lowest levels. Hence, these designs are useful in avoiding experiments performed under extreme conditions, for which unsatisfactory results may occur. Therefore, through these designs one can enhance the production of any product using fewer experiments at a low cost. Hence, the increasing demand of ergot alkaloids, because of their pharmaceutical and therapeutic nature, is compelling to establish a significant and cheaper process of the production of ergot alkaloids for commercial purposes [15].

The production of microbial ergot alkaloids cannot be achieved without the movement and permanence of the producers and this can be enhanced by inducing mutation in them. The effect of mutations on the biosynthesis of alkaloids is more reliable and applicable because of its speculative 
importance. The genetics of alkaloids formation has not been widely studied and the effect of mutations using physical (UV-light) and chemical (EMS) mutagens on the biosynthesis of alkaloids can achieve positive results using various strains of fungi such as Penicillium roquefortii, Aspergillus niger, Trichoderma viride [8].

In the light of the above scenario, the present study was designed after keeping in mind the significance of ergot alkaloids. The ergot alkaloids are ergotamine derivatives used to treat many ailments. They are significant in increasing the strength of uterine contractions during child birth and are used to limit postpartum bleeding. Many of the pharmaceutical companies use these derivatives and their extracts in various drugs such as for the treatment of migraine headaches as well. The main objective of the present study was the production and extraction of commercially important ergot alkaloids from fungal species using fermentation technique to contribute to the field of pharmaceutical industry. Hence, this research was designed to synthesize ergot alkaloids from fungi because the life cycle of fungi is very small than plants and it can produce large amounts of ergot alkaloids in a very short period of time. Therefore, Penicillium citrinum was used in the present research for the production of ergot alkaloids within a very short period of time using a sophisticated statistical technique of response surface methodology during fermentation studies. The ergot alkaloids which are produced during this study were identified as ergocryptine and ergoclavine which are very useful as pharmaceutical and therapeutic agents and can be used in various drug formulations.

\section{Results}

\subsection{Strain Improvement}

\subsubsection{Impact of Physical and Chemical Mutagen on Penicillium citrinum}

The wild strain of Penicillium citrinum was subjected to mutation by UV irradiation and ethyl methane sulfonate (EMS) reagent.

Impact of UV Irradiations

The survival percentage of mutated colonies of Penicillium citrinum was decreased with the increase in exposure time under UV light. The minimum survival rate was found as $2.04 \%$ after $150 \mathrm{~min}$ of UV exposure (Table 1). The colonies survived at $150 \mathrm{~min}$ of exposure were grown on malt extract and agar medium as shown in Figure 1.

Table 1. Survival rate of colonies of Penicillium citrinum after exposure in ultraviolet (UV) light.

\begin{tabular}{ccc}
\hline \multirow{2}{*}{$\begin{array}{c}\text { UV Exposure Time } \\
(\mathbf{m i n})\end{array}$} & \multicolumn{2}{c}{ Penicillium citrinum } \\
\cline { 2 - 3 } & No. of Colonies & Survival Rate (\%) \\
\hline 0 & 49 & 100 \\
\hline 15 & 44 & 89.7 \\
\hline 30 & 41 & 83.6 \\
\hline 45 & 37 & 75.5 \\
\hline 60 & 31 & 63.2 \\
\hline 75 & 28 & 57.1 \\
\hline 90 & 20 & 40.8 \\
\hline 105 & 14 & 28.5 \\
\hline 120 & 7 & 14.2 \\
\hline 135 & 3 & 6.12 \\
\hline 150 & 1 & 2.04 \\
\hline
\end{tabular}




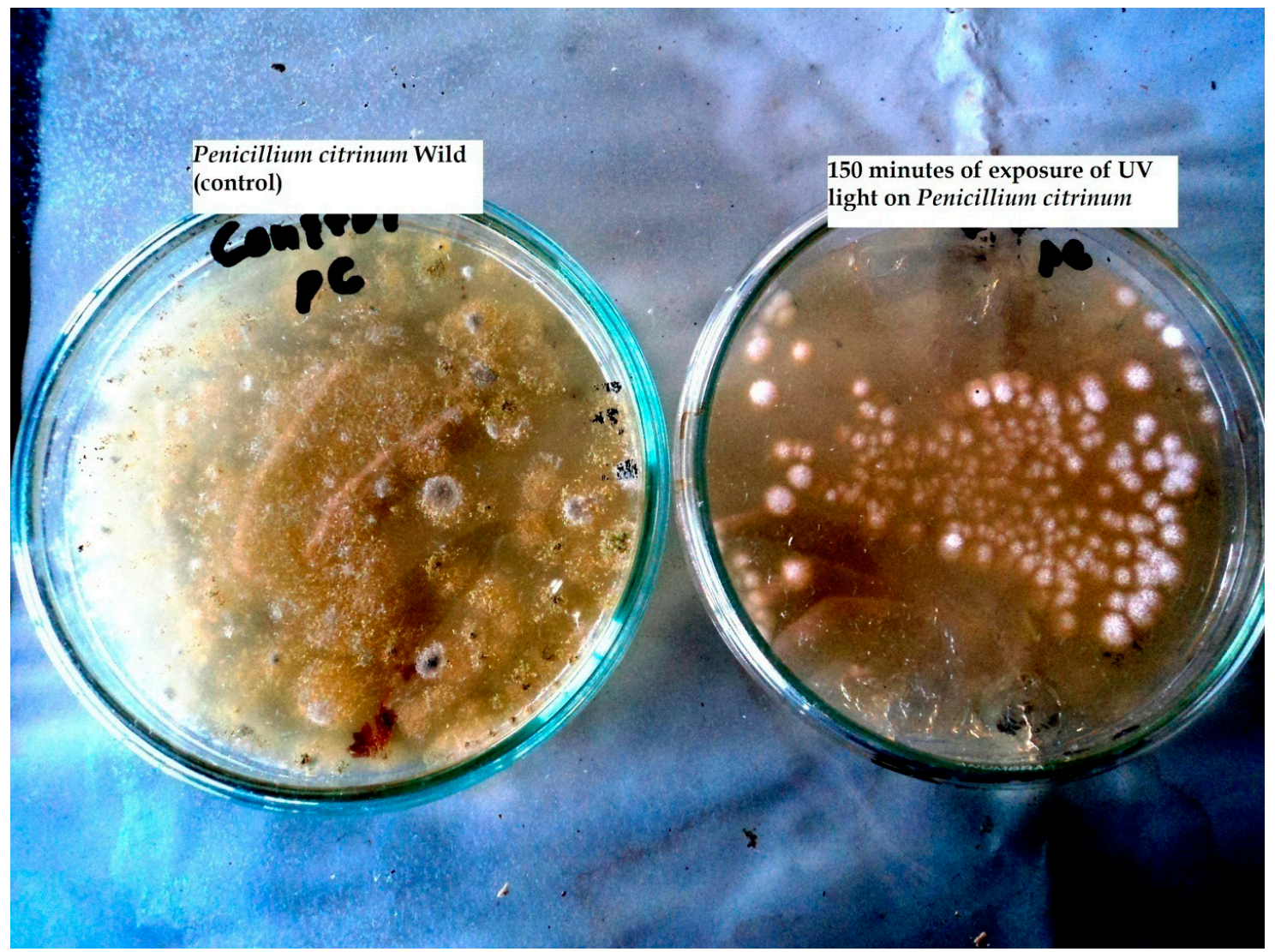

Figure 1. Colonies of Penicillium citrinum before and after exposure to UV.

Impact of Ethyl Methane Sulfonate (EMS)

After exposure in EMS for variable times, the survival rate was found to be decreased rapidly and after $30 \mathrm{~min}$ of exposure no colony of Penicillium citrinum were found alive (Table 2). Minimum survival rate (3.2\%) was recorded after 25 min of exposure in EMS and the presence of only a few colonies were observed (Figures 2 and 3).

Table 2. Survival rate of colonies Penicillium citrinum in Ethyl Methane Sulfonate (EMS).

\begin{tabular}{ccc}
\hline \multirow{2}{*}{$\begin{array}{c}\text { EMS Exposure Time } \\
(\text { min) }\end{array}$} & \multicolumn{2}{c}{ Penicillium citrinum } \\
\cline { 2 - 3 } & No. of Colonies & Survival Rate (\%) \\
\hline 0 & 31 & 100 \\
\hline 10 & 25 & 80.6 \\
\hline 15 & 14 & 45.1 \\
\hline 20 & 7 & 22.5 \\
\hline 25 & 1 & 3.2 \\
\hline 30 & 0 & 0 \\
\hline
\end{tabular}



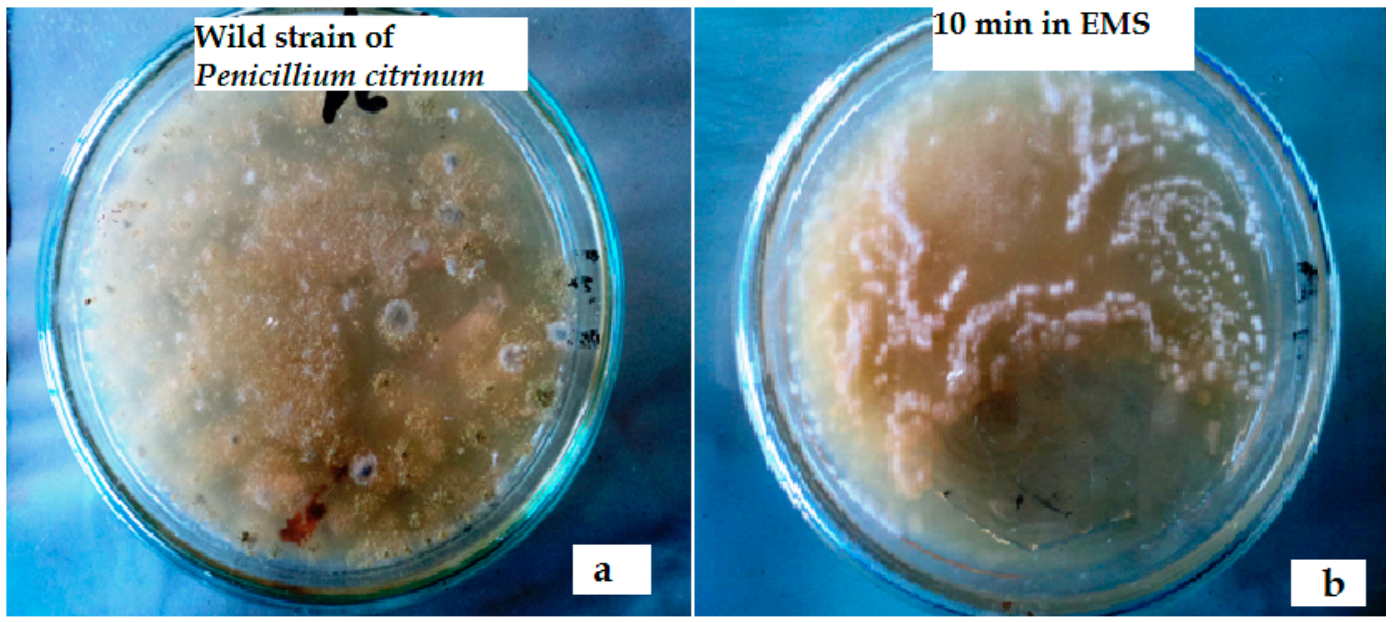

Figure 2. (a) Colonies of Penicillium citrinum without ethyl methane sulfonate (EMS) treatment. (b) P. citrinum colonies after 10 min of exposure in EMS.
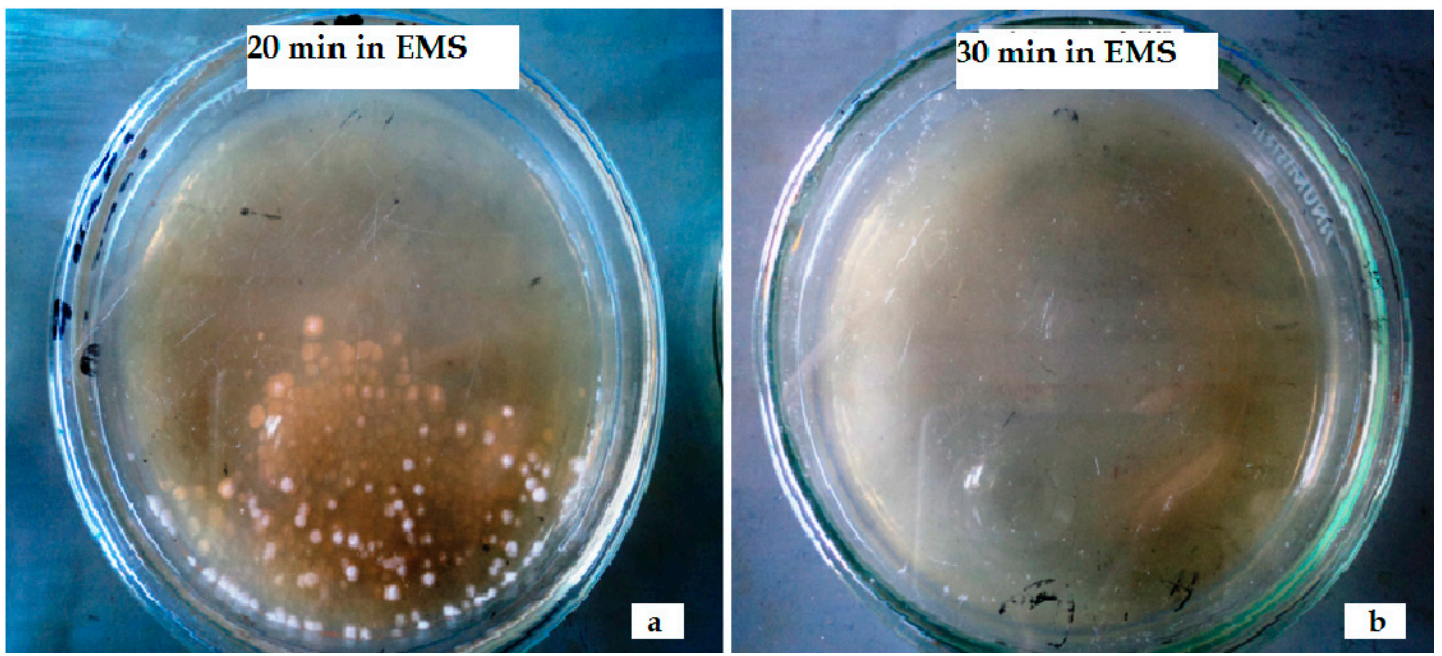

Figure 3. (a) Colonies of Penicillium citrinum after 20 min of exposure in EMS; (b) appearance of no fungal colonies after $30 \mathrm{~min}$ of exposure in EMS.

UV and EMS Mutated Strains for Ergot Alkaloids Synthesis

All of the mutated strains were screened for their ability to produce ergot alkaloids and PCUV-4 and PCEMS-3 were found as the useful mutants producing the maximum ergot alkaloids as $4.56 \pm 0.01 \mathrm{mg} / \mathrm{mL}$ and $2.99 \pm 0.005 \mathrm{mg} / \mathrm{mL}$, respectively (Table 3).

Table 3. UV and EMS mutant screening.

\begin{tabular}{cccccc}
\hline $\begin{array}{c}\text { UV treated Strains of } \\
\text { Penicillium citrinum }\end{array}$ & $\begin{array}{c}\text { Extracellular Extract } \\
\mathbf{( m g / m L )}\end{array}$ & $\begin{array}{c}\text { Intracellular Extract } \\
\mathbf{( m g / m L})\end{array}$ & $\begin{array}{c}\text { EMS treated Strains of } \\
\text { Penicillium citrinum }\end{array}$ & $\begin{array}{c}\text { Extracellular } \\
\text { Extract } \\
(\mathbf{m g} / \mathbf{m L})\end{array}$ & $\begin{array}{c}\text { Intracellular Extract } \\
(\mathbf{m g} / \mathbf{m L})\end{array}$ \\
\hline PCUV-1 & $1.49 \pm 0.01$ & $1.05 \pm 0.02$ & PCEMS-1 & $1.84 \pm 0.02$ & $1.58 \pm 0.01$ \\
\hline PCUV-2 & $1.68 \pm 0.02$ & $1.65 \pm 0.03$ & PCEMS-2 & $2.5 \pm 0.01$ & $2.10 \pm 0.03$ \\
\hline PCUV-3 & $2.56 \pm 0.05$ & $1.65 \pm 0.01$ & PCEMS-3 & $2.99 \pm 0.005^{*}$ & $2.78 \pm 0.04^{*}$ \\
\hline PCUV-4 & $4.56 \pm 0.01^{*}$ & $1.89 \pm 0.03 *$ & Wild & & \\
\hline PCUV-5 & $3.86 \pm 0.02$ & $1.34 \pm 0.01$ & & & \\
\hline Wild & $2.45 \pm 0.03$ & $1.66 \pm 0.01$ & & & \\
\hline
\end{tabular}

Each value is an average of three replicates and \pm indicates the standard deviation of these replicates. And ${ }^{*} p<0.05$. 


\subsection{Response Surface Methodology}

The Plackett-Burman and Box-Behnken designs were used for the screening and identification of components of the fermentation medium using PCUV-4 as experimental organism.

\subsubsection{Screening Step Using PBD}

Plackett-Burman design (PBD) was employed for screening of fermentation factors such as yeast extract, sucrose, asparagines, succinic acid, tryptophan, $\mathrm{KH}_{2} \mathrm{PO}_{4}, \mathrm{MgSO}_{4}, \mathrm{FeSO}_{4}$ and $\mathrm{pH}$. The highest yield $(14.74 \pm 0.01 \mathrm{mg} / \mathrm{mL})$ was achieved from run No. 2 and the lowest was observed from run No. 3 $(0.36 \pm 0.02 \mathrm{mg} / \mathrm{mL})$ as given in Table 4 . The Pareto chart was used to show the effect of all fermentation ingredients on ergot alkaloids production (Figure 4).

Table 4. Screening of variables using Plackett-Burman design (PBD).

\begin{tabular}{cc}
\hline Run. & Yield of Ergot Alkaloids $(\mathrm{mg} / \mathrm{mL})$ \\
\hline 1 & $11.84 \pm 0.1$ \\
\hline 2 & $14.76 \pm 0.01 *$ \\
\hline 3 & $0.36 \pm 0.03$ \\
\hline 4 & $6.53 \pm 0.01$ \\
\hline 5 & $10.96 \pm 0.01$ \\
\hline 6 & $11.95 \pm 0.02$ \\
\hline 7 & $0.74 \pm 0.04$ \\
\hline 8 & $5.38 \pm 0.1$ \\
\hline 9 & $11.79 \pm 0.03$ \\
\hline 10 & $7.76 \pm 0.05$ \\
\hline 11 & $0.24 \pm 0.02$ \\
\hline 12 & $13.02 \pm 0.03$
\end{tabular}

Each value is an average of three replicates and " \pm " indicates the standard deviation among three replicates. $* p<0.05$.

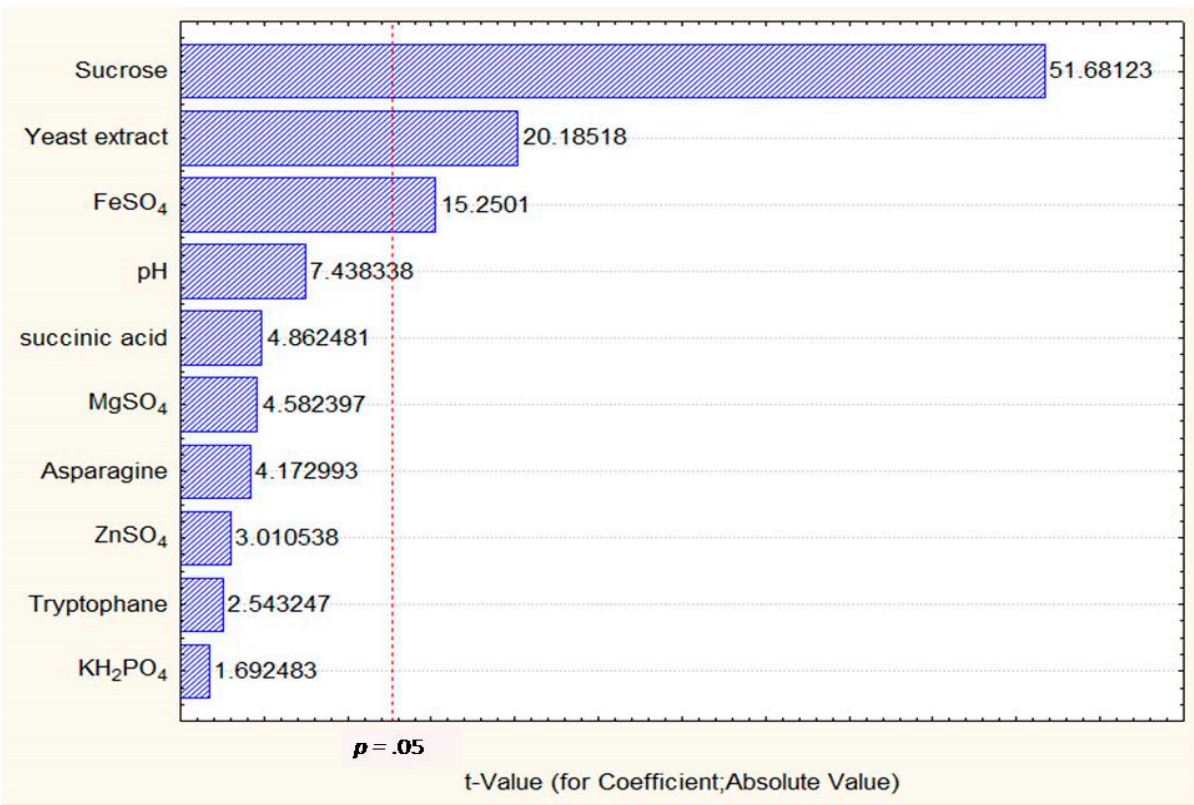

Figure 4. Pareto chart showing the significant variables, i.e., sucrose, yeast extract and $\mathrm{FeSO}_{4}$ influencing the production of ergot alkaloid yield by Penicillium citrinum. 


\section{ANOVA for PBD Model}

The ANOVA (analysis of Variance) of PBD is given in Table 5 that described the factors with $p<0.05$ were considered significant for the production of ergot alkaloids. From Table 5, it was clearly indicated that sucrose, yeast extract and $\mathrm{FeSO}_{4}$ were significantly influencing the yield of ergot alkaloids. In addition, the coefficient of determination $\left(R^{2}\right)$ of the model was 0.9996 which explained $99.96 \%$ variance in data. Sucrose had a confidence level of above $95 \%$ in comparison to other variables and thus considered highly significant for ergot alkaloids production.

Table 5. Analysis of variance for using PBD.

\begin{tabular}{cccccc}
\hline Source & Sum of Squares & Degree of Freedom & Mean Square & F-Value & $p$-Value \\
\hline Intercept & 0.46 & 1 & 0.46 & 8.26 & 0.21 \\
\hline Sucrose & 147.78 & 1 & 147.78 & 2670.95 & 0.012 \\
\hline yeast extract & 22.54 & 1 & 22.54 & 4.7 .44 & 0.032 \\
\hline Succinic acid & 1.30 & 1 & 1.30 & 23.64 & 0.13 \\
\hline $\mathrm{MgSO}_{4}$ & 1.16 & 1 & 1.16 & 20.96 & 0.14 \\
\hline $\mathrm{KH}_{2} \mathrm{PO}_{4}$ & 0.16 & 1 & 0.16 & 2.86 & 0.34 \\
\hline $\mathrm{FeSO}_{4}$ & 12.87 & 1 & 12.87 & 232.57 & 0.042 \\
\hline $\mathrm{ZnSO}_{4}$ & 0.50 & 1 & 0.50 & 9.06 & 0.20 \\
\hline Asparagine & 0.96 & 1 & 0.96 & 17.41 & 0.15 \\
\hline Tryptophan & 0.36 & 1 & 0.36 & 6.47 & 0.24 \\
\hline pH & 3.06 & 1 & 3.06 & 55.33 & 0.085 \\
\hline Error & 0.06 & 1 & 0.06 & & \\
\hline
\end{tabular}

\subsubsection{Identification of Significant Factors Using Box-Behnken design (BBD)}

Box-Behnken design (BBD) was applied to optimize the selected variables (Sucrose, yeast extract and $\mathrm{FeSO}_{4}$ ) and to find out the effect of their mutual impact on the production of ergot alkaloids. The yield of ergot alkaloids obtained from extracellular extracts of Penicillium citrinum ranged from $13.50 \mathrm{mg} / \mathrm{mL}$ to $35.60 \mathrm{mg} / \mathrm{mL}$, respectively. The observed values of ergot were compared with predicted values, as presented in Table 6. Maximum ergot alkaloids yield was observed from extracellular extract of run No. $13(35.60 \mathrm{mg} / \mathrm{mL})$ and it was also compared with the predicted value $(35.60 \mathrm{mg} / \mathrm{mL})$. The lowest value of ergot alkaloids yield was found from run No. $6(13.50 \mathrm{mg} / \mathrm{mL})$ and it was almost similar to the predicted value $(14.16 \mathrm{mg} / \mathrm{mL})$ (Table 6$)$. These values were calculated from the polynomial equation as described in Section 5.5.2.

Table 6. Observed and predicted values of yield using Box-Behnken design (BBD).

\begin{tabular}{cccccc}
\hline Runs & $\begin{array}{c}\text { Sucrose } \\
(\mathbf{g} / \mathbf{1 0 0} \mathbf{~ m L})\end{array}$ & $\begin{array}{c}\text { Yeast Extract } \\
(\mathbf{g} / \mathbf{1 0 0} \mathbf{~ m L})\end{array}$ & $\begin{array}{c}\mathbf{F e S O}_{\mathbf{4}} \\
(\mathbf{g} / \mathbf{1 0 0} \mathbf{~ m L})\end{array}$ & $\begin{array}{c}\text { Alkaloids Yield (Observed) } \\
\mathbf{m g} / \mathbf{m l}\end{array}$ & $\begin{array}{c}\text { Alkaloids Yield } \\
\text { (Predicted) } \\
\mathbf{m g} / \mathbf{m l}\end{array}$ \\
\hline 1. & 41 & 5 & 0.06 & 22.50 & 21.75 \\
\hline 2. & 41 & 39 & 0.06 & 16.00 & 17.42 \\
\hline 3. & 41 & 22 & 0.01 & 24.55 & 24.32 \\
\hline 4. & 41 & 22 & 0.11 & 27.79 & 27.79 \\
\hline 5. & 5 & 5 & 0.06 & 18.90 & 17.94 \\
\hline 6. & 5 & 39 & 0.06 & $13.50 *$ & 20.06 \\
\hline 7. & 5 & 22 & 0.01 & 20.40 & 25.30 \\
\hline 8. & 5 & 22 & 0.11 & 16.87 & 16.65 \\
\hline 9. & 23 & 5 & 0.01 & 17.90 & 25.56 \\
\hline 10. & 23 & 39 & 0.01 & 25.20 & 16.75 \\
\hline 11. & 23 & 5 & 0.11 & 17.60 & 35.60 \\
\hline 12. & 23 & 39 & 0.11 & 35.60 &
\end{tabular}




\section{ANOVA for BBD Model}

The analysis of variance of the three factors (Sucrose, yeast extract and $\mathrm{FeSO}_{4}$ ) indicated that the ergot alkaloids activity can be well described by the polynomial model with a high coefficient of determination $\left(\mathrm{R}^{2}=0.95\right)$. The statistical model presented in Table 7 shows that each (sucrose, yeast extract and $\mathrm{FeSO}_{4}$ ) had a significant impact on the production of ergot alkaloids. It was investigated that yeast extract remarkably influenced the production of ergot alkaloids in extracellular extracts of Penicillium citrinum with a value of $290.84 \mathrm{mg} / \mathrm{mL}$. Among the combined interaction effect of these three significant variables (sucrose-yeast extract, sucrose- $\mathrm{FeSO}_{4}$ and yeast extract-FeSO $\mathrm{F}_{4}$ ), the combination of yeast extract- $\mathrm{FeSO}_{4}$ interaction was found to be more significant in extracellular extract $(23.52 \mathrm{mg} / \mathrm{mL})$. Lowest yield of ergot alkaloids was obtained in the combination of "Sucrose-FeSO $\mathrm{S}_{4}$ ". Through this statistical model the insignificant interaction coefficients were eliminated, and the final polynomial equation was expressed as follows:

$$
\begin{gathered}
Y=-21.244-19.656 x^{1}+3.148 x^{2}+55.350 x^{3}-1.791 x 1^{2}-0.02 x 2^{2}+55.350 x 3^{2} \\
-0.019 x^{1} x^{2}-0.100 x^{1} x^{3}+0.243 x^{2} x^{3}
\end{gathered}
$$

where ' $Y^{\prime}$ was the predicted response, ' $X^{1}, X^{2}, X^{3^{\prime}}$ were the values of sucrose, yeast extract and $\mathrm{FeSO}_{4}$, respectively. Through this model it can be assumed that the model accurately represents the data in experimental region. This was confirmed by the residual analysis of the data which is not presented here. The main results of this study are presented in Figures 5-7, which shows the expected ergot alkaloids production and correlation between variables in three dimensional plots.

\begin{tabular}{|c|c|c|c|c|c|c|}
\hline Variable & Sum of Square & Degree of Freedom & Means Square & F-Value & $p$-Value & $t$-Value \\
\hline Intercept & 175.21 & 1 & 175.21 & 167.58 & 0.001 & -12.55 \\
\hline Sucrose & 121.31 & 1 & 121.31 & 11.33 & 0.002 & 10.07 \\
\hline Sucrose $^{2}$ & 116.22 & 1 & 116.22 & 119.58 & 0.002 & -10.24 \\
\hline yeast Extract & 294.94 & 1 & 294.94 & 259.87 & 0.000 & 16.12 \\
\hline yeast Extract ${ }^{2}$ & 308.41 & 1 & 308.41 & 285.67 & 0.000 & -16.63 \\
\hline $\mathrm{FeSO}_{4}$ & 75.62 & 1 & 75.62 & 76.79 & 0.004 & 8.17 \\
\hline $\mathrm{FeSO}_{4}{ }^{2}$ & 49.91 & 1 & 49.91 & 39.89 & 0.006 & -6.91 \\
\hline Sucrose, yeast Extract & 3.16 & 1 & 3.16 & 2.01 & 0.251 & -1.42 \\
\hline Sucrose, $\mathrm{FeSO}_{4}$ & 0.03 & 1 & 0.03 & 0.04 & 0.862 & -0.18 \\
\hline yeast Extract, $\mathrm{FeSO}_{4}$ & 24.61 & 1 & 24.61 & 21.01 & 0.019 & -4.58 \\
\hline
\end{tabular}

Table 7. Analysis of variance using BBD.

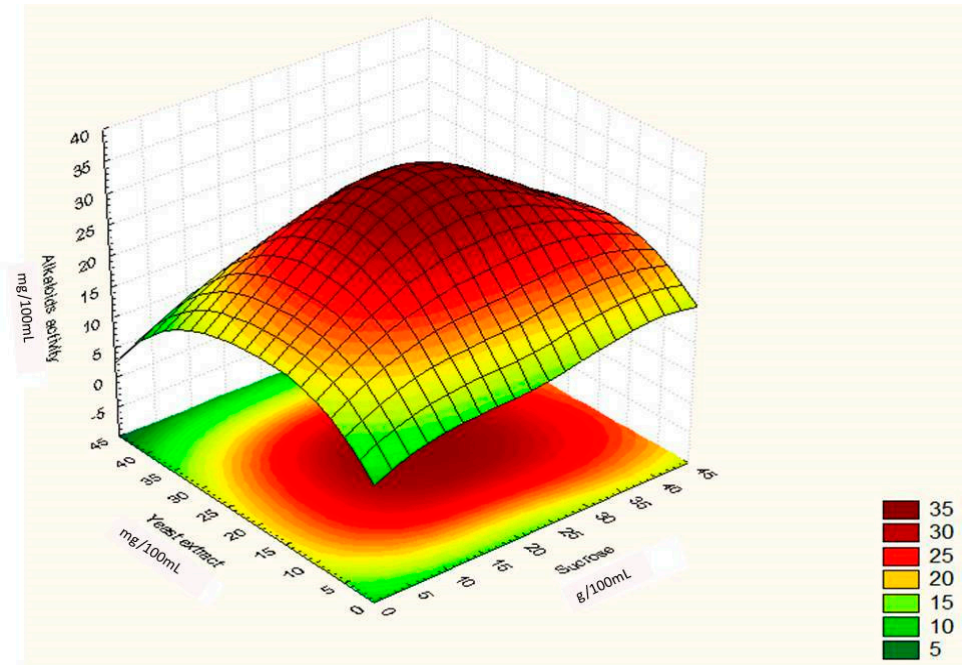

Figure 5. Surface graph showing interactive effect of sucrose and yeast extract on ergot alkaloid production by Penicillium citrinum. 


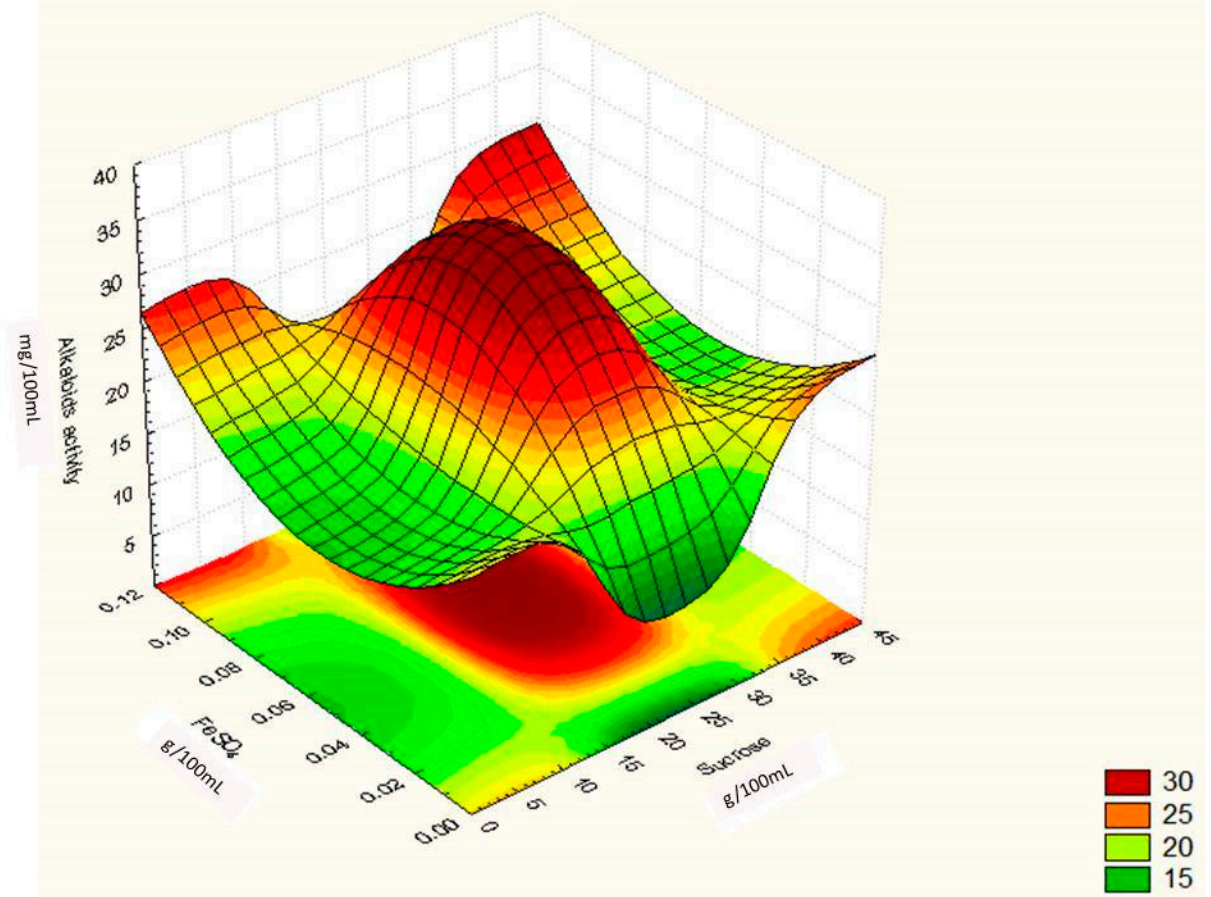

Figure 6. Surface graph showing interactive effect of sucrose and $\mathrm{FeSO}_{4}$ on ergot alkaloid production by Penicillium citrinum.

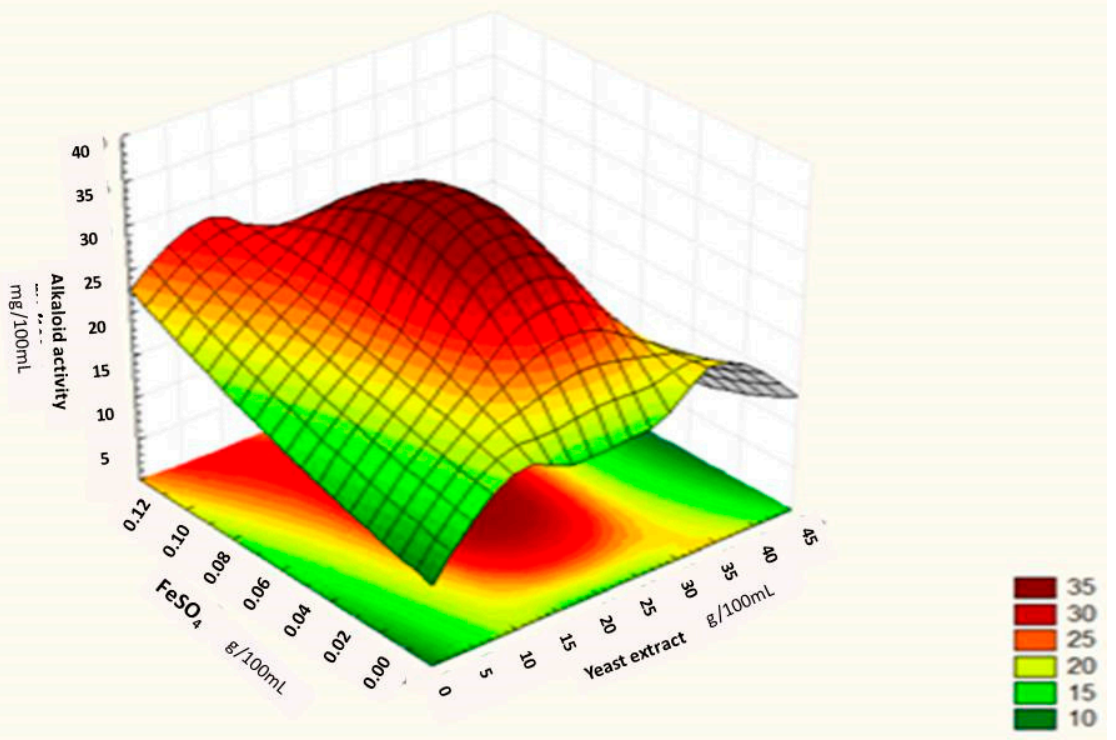

Figure 7. Surface graph showing interactive effect of yeast extract and $\mathrm{FeSO}_{4}$ on ergot alkaloid production by Penicillium citrinum.

Figure 5.shows significant additive effect of sucrose and yeast extract on the yield of ergot alkaloids. This two factor impact means that both were dependent on each other for ergot alkaloids production. The shape of the curve and the dark red color in Figure 6 also indicates that maximum alkaloids yield was obtained when $41 \mathrm{~g} / 100 \mathrm{~mL}$ of sucrose and $39 \mathrm{~g} / 100 \mathrm{~mL}$ of yeast extract was added in the experimental run.

Figure 6 illustrates that increasing the sucrose value at the moderate levels of $\mathrm{FeSO}_{4}$ in the fermentation medium led to maximum ergot alkaloids production. The optimum value deduced from 
Figure 6 is in accordance with the mathematically calculated optimum points. The dome shape of the curve shows the significant mutual interaction of sucrose and $\mathrm{FeSO}_{4}$.

In Figure 7, the additive effect of yeast extract and $\mathrm{FeSO}_{4}$ was found and it was observed that maximum ergot alkaloids activity was measured when fermentation medium was supplemented with $0.11 \mathrm{~g} / 100 \mathrm{~mL}$ of $\mathrm{FeSO}_{4}$ and $39 \mathrm{~g} / 100 \mathrm{~mL}$ of yeast extract. The results obtained as well as predicted by Box-Behnken design showed that a combination of $41 \mathrm{~g} / 100 \mathrm{~mL}$ of sucrose, $39 \mathrm{~g} / 100 \mathrm{~mL}$ of yeast extract and $0.11 \mathrm{~g} / 100 \mathrm{~mL}$ of FeSO 4 would favor maximum ergot alkaloids production $(290.84 \mathrm{mg} / \mathrm{mL})$.

Regression Analysis for Ergot Alkaloids Production and Comparison between the Observed and Predicted Response

The regression analysis was performed to predict the future response $Y$ (ergot alkaloids yield) corresponding to the experimental data values. The regression analysis explained the difference between the observed and predicted values of the yield $(\mathrm{Y})$. This was calculated by using the following equation:

$$
\mathrm{e}=\mathrm{Y}-\mathrm{Y}^{\prime}
$$

where ' $\mathrm{e}$ ' represents residues, ' $\mathrm{Y}$ ' is the observed response or yield and ' $\mathrm{Y}$ ' is the predicted response or yield of ergot alkaloids. The Figure 8 clearly indicates a non-random pattern among the predicted and observed values for the production of ergot alkaloids by Penicillium citrinum (PCUV-4)and a high degree of similarity was observed between the predicted $(35 \mathrm{mg} / \mathrm{mL})$ and observed response $(35 \mathrm{mg} / \mathrm{mL})$ of ergot alkaloids. It was also found that this model was a better fit model to describe the effect of optimized factors (sucrose, yeast extract and $\mathrm{FeSO}_{4}$ ) as significant independent variables on the yield of ergot alkaloids.

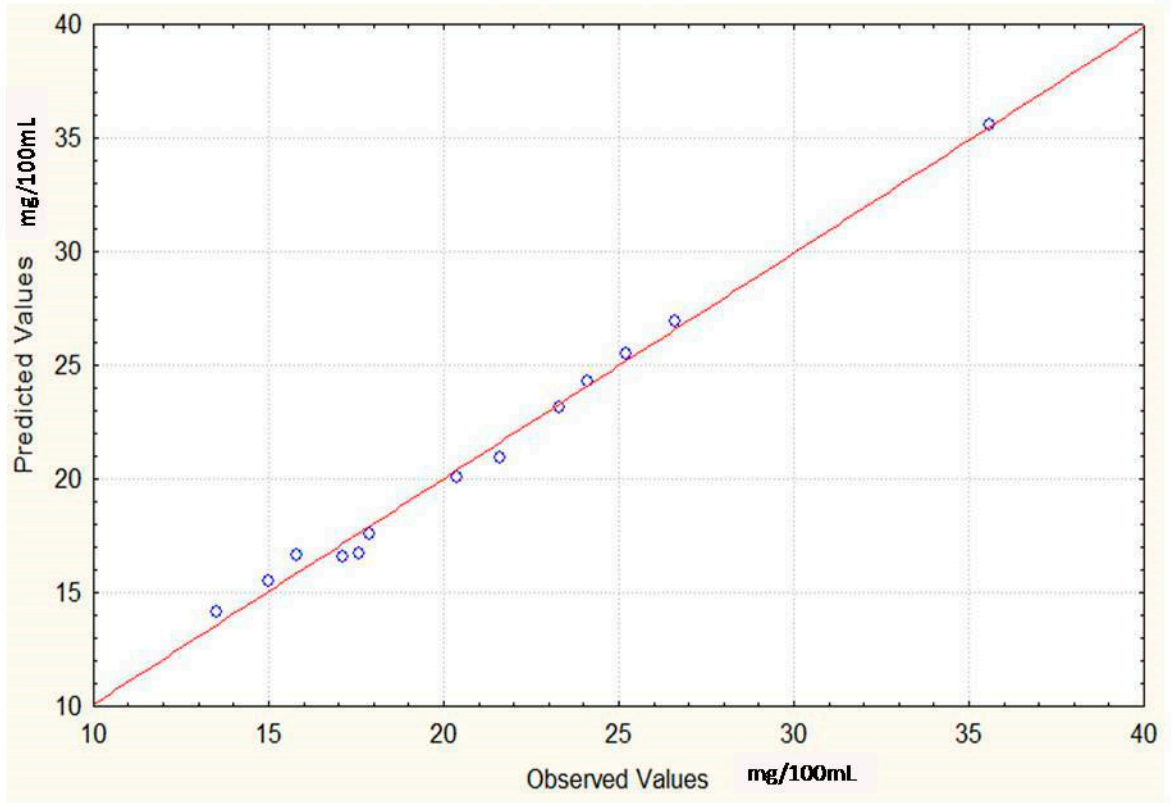

Figure 8. Predicted values of ergot alkaloids production by Penicillium citrinum using BBD.

\section{Discussion}

Fungal organisms are considered as the depository of important secondary metabolites and many them perform significant biologic functions. These fungal species are cosmopolitan in nature and have a potential to fulfill the demand of drugs in the pharmaceutical industry [16]. These amino-alkaloids can also be obtained from higher and lower plants in lysergic acid alkaloids and gliotoxins forms [17].

In this investigation, the wild strain of Penicillium citrinum was subjected to physical and chemical mutagens to enhance its capability for ergot alkaloids production. The wild strain of Penicillium citrinum 
was exposed under UV irradiation and it was observed that death of the fungal species is accredited with the harmful effects of UV irradiations. Onyegeme-Okerentet al. [18] described that exposure to UV irradiation can be used for genetic variations in many species of microorganisms. This classical technique was first time used in the 1950s to synthesize maximum amount of penicillin from Penicillium chrysogenum Q-176. They also mutated two strains of Penicillium chrysogenum (UVP1 and UVP2) after UV treatment for 20 and $25 \mathrm{~min}$. Veerapagu et al. [19] and Moussa [20] also concluded from their studies that with the increase in the amount of irradiations, an increase in the yield of products can be observed, but sometime the production of the fungal product can be decreased due to negative impacts of the irradiations on DNA of the organism. Ethyl methane-sulfonate (EMS) is another powerful carcinogenic mutagen that can cause significant genetic variations in microorganisms. In the present study, Penicillium citrinum was exposed in EMS for different time intervals. The lethality of fungal organism was found to be increased with the increase in exposure time and survival percentage of the colonies were found to be decreased (Table 2). El-Bondkly and Abeer [21] also treated Penicillium roquefortii with different doses of concentrated EMS and found similar results.

Furthermore, in the present study, the maximum yield of ergot alkaloids was achieved from PCUV-4 and PCEMS-3 mutant strains and their yield was also compared with the yield of wild strains of Penicillium citrinum (Table 3). Hamad et al. [22] also found UV irradiation to be more effective than EMS due to strong mutagenic impact of UV light on the DNA of the strain. The study also reported UV mutagenic treatments to be more efficient than the chemical treatments to get strong mutations in the DNA structure of the organism. Nadeem [23] also improved the strain by employing UV, NTG and MMS for the synthesis of alkaline proteases and found the similar results. He concluded that all physical and chemical mutagens can alter the DNA structure for enviable outcomes.

In recent studies, statistical models were reported as effective tools for the optimization of fermentation parameters in biotechnology. There are several studies for the optimization of culture conditions using these sophisticated statistical procedures [24,25]. Therefore, during the present investigation, response surface methodology (RSM) was applied as an empirical statistical technique which can be used for regression analysis of data, received from multi-factorial experimental designs. This technique is very popular for screening and optimization of various parameters of fermentation experiment $[3,26]$. In this investigation, Plackett-Burman design (PBD) and Box-Behnken design (BBD) were used for optimizing and screening of ingredients used to get the maximum amount of ergot alkaloids (Tables 4 and 5). In the first step of screening the fermentation parameters, sucrose, yeast extract and $\mathrm{FeSO}_{4}$ were found as the most considerable ingredients as analyzed by PBD model. $\mathrm{Wu}$ et al. [27] screened some important ingredients of fermentation experiment for synthesizing fumigaclavine C and helvolic acid from Aspergillus fumigatus CY018 strain, using the same model of PBD. They also concluded that $\mathrm{pH}$, amount of phosphate and the size of inoculums were considerable ingredients in the production of fumigaclavine $C$ and helvolic acid. Rubina et al. [28] screened various fermentation medium formulations for the synthesis of a thermostable lipase using a recombinant Escherichia coli strain BL21. They used a similar Plackett-Burman design and found that glucose, $\mathrm{NaCl}$, temperature and incubation time were the most significant variables influencing lipase production. The $\mathrm{R}^{2}$ value (0.979) of their study proved that PBD is highly significant model to screen the initial parameters to get the maximum lipase yield. Substantial increases in the yield of many products ranging from five to six fold using similar RSM techniques were reported by several researchers [29,30].

The next step of the present study was to apply Box-Behnken design (BBD) to optimize the yield of the product (ergot alkaloids) during fermentation studies. In this the first step was to identify the independent variables that affect the ergot alkaloids production and the next step was to study their mutual impacts on dependent response. The experiments of BBD were carried out to obtain a quadratic model consisting of 13 runs which are mentioned in Table 6 with their experimental results. Regression analysis and the analysis of variance was also performed for the three significant variables (sucrose, yeast extract and $\mathrm{FeSO}_{4}$ ). Through BBD, non-significant factors were eliminated, and the reduced model was expressed in a polynomial equation. Through the results of BBD of the present 
study, it can be assumed that the model accurately represents the data in the experimental region. Therefore, a great enhancement in the yield of ergot alkaloids was achieved using the fewer runs using less expensive statistical method. Lee et al. [31] applied the similar BBD in their experiments and reported an enzyme activity titer of $520 \mathrm{U} / \mathrm{L}$ for $B$. thermoleovorans using olive oil in the fermentation medium, which was higher than the activities attained by other thermophilic bacilli.

Statistical designs are significant tools which can also be used to find out the interactive influences of fermentation factors on the process performance. Therefore, during present study, the combined interactions of sucrose, yeast extract and $\mathrm{FeSO}_{4}$ were also analyzed using BBD. It was observed that the combination of yeast extract and $\mathrm{FeSO}_{4}$ is more significant for obtaining the maximum yield of ergot alkaloids from extracts of Penicillium citrinum (Table 6). Venil and Lakshmanaperumalsamy [14] applied the similar Box-Behnken design (BBD) for analyzing the interaction effect of temperature, $\left(\mathrm{NH}_{4}\right)_{2} \mathrm{PO}_{4}$ and trace salts on the prodigiosin yield. They also generated a second-order polynomial equation to identify the relationship between the prodigiosin yield and three selected factors. Their fermentation medium was optimized containing $6 \mathrm{~g} / \mathrm{L}$ of $\left(\mathrm{NH}_{4}\right)_{2} \mathrm{PO}_{4}$ and trace salts $(0.6 \mathrm{~g} / \mathrm{L})$ and incubation temperature was $30^{\circ} \mathrm{C}$ for the enhanced production of the product. The study reported that observed responses of prodigiosin were almost equal to the predicted responses of BBD model as mentioned in the present investigation. In the end of their research, they concluded that the high correlation between the observed and predicted values of their product indicates the validity of BBD model.

Results obtained in this study are comparable to Wang et al. [32] who applied the same BBD model to find out the impact of glucose, peptones and $\mathrm{KH}_{2} \mathrm{PO}_{4}$ on the cell biomass formation and reported it as an efficient statistical tool. They also obtained a quadratic model and appraised the quadratic results and central points to estimate the pure process variability with chitosanase activity as response. The three components significantly affected the chitosanase activity optimized through the similar BBD model of RSM. Krishnaa et al. [33] optimized the role of $\mathrm{pH}$ on the biomass yield of Borasus flabellifer in 15 runs of fermentation experiment and concluded that BBD was the best fit model to analyze the maximum runs of experiments in a single batch. The results of the BBD model of this study are similar with Amara [34] who optimized the fermentation conditions for the synthesis of polyhydroxy butyrate by Bacillus species and obtained the highest yield of protease. Yasin et al. [35] applied the similar technique of RSM to enhance the flame retardant properties and low mechanical loss to fabric. They upgraded the system parameters of the finishing treatment given to the fabric using Box-Behnken statistical design. They also observed the impacts of fire resistance and other mechanical properties on fabric quality by analyzing the similar regression equation. The $\mathrm{R}^{2}$ estimation of the responses were above $92 \%$ which demonstrated the significance level of relationship between the predicted and experimental values of the experiment. Cheng et al. [36] optimized the nutritional medium composition required for the chitosanase production by Streptomyces albus YT2 and identified three significant factors (glucose, peptones and $\mathrm{MgSO}_{4}$ ) influencing the chitosanase activity by applying similar BBD statistical design. The study reported that chitosanase yield increased from $11.56 \mathrm{U} / \mathrm{mL}$ to $39.87 \mathrm{U} / \mathrm{mL}$, which is a 3-fold increase in the yield after using the same BBD model.

Therefore, the present investigation revealed that the combination PBD and BBD for screening and optimization purpose were proved as significant and considerable designs for ergot alkaloids synthesis.

\section{Conclusions}

Ergot alkaloids are produced by many organisms and the quantity of ergot alkaloids produced by fungi is relatively less, but it can be improved by applying various techniques. Therefore, some physical and chemical mutagens can enhance the yield of the product by improving DNA of the species. In the present study, UV irradiations were proved to be useful mutagenic agent and PCUV-4 mutant was found to be the significant candidate for the production of ergot alkaloids. Ergot alkaloids were in use since many decades due to their pharmaceutical and therapeutic properties. The present investigation also concluded that response surface methodology (RSM) tools such as Plackett-Burman design (PBD) and Box-Behnken design (BBD) are more reliable statistical models to increase the yield of ergot 
alkaloids in a single step. It was also concluded that these fermentation studies on ergot alkaloids can contribute as an alternative and cost effective methods for the biosynthesis of the important drugs on commercial scales.

\section{Materials and Methods}

\subsection{Microorganism and Its Maintenance}

Penicillium citrinum was collected from the Department of Botany, GC University, Lahore Pakistan and was grown on malt extract agar (MEA) medium slants. The slants were prepared by dissolving $2 \mathrm{~g}$ malt extract and $2 \mathrm{~g}$ agar in $100 \mathrm{~mL}$ of distilled water in a $250 \mathrm{~mL}$ Erlenmeyer flask. The medium was sterilized in autoclaved at $121^{\circ} \mathrm{C}$ under $15 \mathrm{lb} / \mathrm{inch}^{2}$ for $15 \mathrm{~min}$. The mature culture of Penicillium citrinum was streaked aseptically to the slants containing $5 \mathrm{~mL}$ of MEA medium in a test tube. These inoculated slants were kept in incubator for 5 days at $25{ }^{\circ} \mathrm{C}$ so that they may be fully grown. The slants of Penicillium citrinum were subcultured after every two weeks and fully grown slants were stored at $4{ }^{\circ} \mathrm{C}$ for further analytical studies.

\subsection{Strain Improvement}

\subsubsection{Impact of Physical and Chemical Mutagens on Penicillium citrinum}

The wild strains of Penicillium citrinum were mutated using UV irradiation and ethyl methane sulfonate (EMS) for enhancing the yield of ergot alkaloids.

Impact of UV Irradiations

In this step, spore suspension or stock solution of Penicillium citrinum was prepared in $50 \mathrm{~mL}$ of distilled water. The spore suspension was diluted using serial dilution method and $1 \mathrm{~mL}$ of the spore suspension of the last dilution was poured to sterilized Petri plates. The plates containing spore suspensions were placed under $245 \mathrm{~nm}$ UV lamp (purifier horizontal clean bench, Thomas Scientific, Zhejiang, China) to induce mutation for 15, 30, 45, 60, 75, 90, 105, 120, 135 and 150 min, respectively. The UV treated (spore suspension containing) Petri plates were placed overnight in dark. After $24 \mathrm{~h}$, malt extract agar (MEA) medium was transferred to UV exposed Petri plates and placed in incubator at $25{ }^{\circ} \mathrm{C}$ for 10 days. After 10 days, the percentage of living colonies after mutation was compared with wild (control) colonies of strain. This was done following [37].

Impact of Ethyl Methane Sulfonate (EMS)

The wild strain of Penicillium citrinum was also exposed to Ethyl Methane Sulfonate (EMS) for inducing mutation in it. The spore suspension mixture of Penicillium citrinum was prepared in $50 \mathrm{~mL}$ distilled water and diluted by serial dilution method. After a series of dilutions, from the last dilution, $2.5 \mathrm{~mL}$ of spore suspension was transferred to a test tube. Then $1 \mathrm{~mL}$ of EMS (0.3 mL of EMS was dissolved in $0.7 \mathrm{~mL}$ of double distilled water to make $1 \mathrm{~mL}$ solution of EMS) was poured in the test tube containing the spore suspension. The mixture was shaken properly and $1 \mathrm{~mL}$ of it was transferred to the sterilized Petri plates. These Petri plates were exposed in EMS solution for 10, 15, 20, 25 and 30 min, respectively. After EMS exposure, malt extract agar (MEA) medium was poured in Petri plates and plates were incubated at $25^{\circ} \mathrm{C}$ for 10 days. After 10 days of incubation, the survival percentage of wild and mutant colonies was noted. This method was also done after [37].

\subsubsection{Calculation of Survival Percentage of Colonies}

Survival percentage of colonies was calculated using the following formula:

$$
\text { Survival rate }(\%)=\frac{\text { No. of Mutated Colonies }}{\text { No. of Wild Colonies }} \times 100
$$




\subsection{Maintenance of Mutant Strain}

The mutant strains of Penicillium citrinum were grown on MEA medium slants at $25^{\circ} \mathrm{C}$ for 10 days. The fully grown mature slants were kept in refrigerator at $4{ }^{\circ} \mathrm{C}$ for further analyses.

\subsubsection{Selection of Best UV Mutant for the Production of Ergot Alkaloids}

The living colonies of Penicillium citrinum after 135 and 150 min of UV exposure were grown on MEA medium slants and named as PCUV-1, PCUV-2, PCUV-3, PCUV-4 and PCUV-5, respectively. These mutants were provided with self-modified, optimized fermentation medium to observe the best producer of ergot alkaloids. The composition of fermentation medium is presented in Table 8 .

Table 8. Fermentation medium for the production of ergot alkaloids by wild and mutant strains.

\begin{tabular}{cc}
\hline Ingredients. & g/100 $\mathbf{~ L ~}$ \\
\hline $\mathrm{NH}_{4} \mathrm{Cl}$ & 0.2 \\
\hline Succinic Acid & 0.5 \\
\hline Sucrose & 5 \\
\hline $\mathrm{KH}_{2} \mathrm{PO}_{4}$ & 0.5 \\
\hline Asparagine & 0.5 \\
\hline Tryptophan & 0.5 \\
\hline yeast Extract & 0.5 \\
\hline $\mathrm{MgSO}_{4} \cdot 7 \mathrm{H}_{2} \mathrm{O}$ & 0.03 \\
\hline $\mathrm{FeSO}_{4}$ & 0.01 \\
\hline $\mathrm{ZnSO}_{4}$ & 0.002 \\
\hline Fermentation Conditions \\
\hline Incubation Time (Days) \\
\hline Inoculum Size (ml) \\
\hline pH \\
\hline
\end{tabular}

\subsubsection{Selection of Best EMS Mutant for the Production of Ergot Alkaloids}

The fungal colonies grown after 25 min of EMS exposure were streaked on MEA slants and named as PCEMS-1, PCEMS-2 and PCEMS-3, respectively. The self-modified optimized fermentation medium (Table 8) was used to produce the ergot alkaloids by EMS mutants. The yield by mutant strains was also compared with the yield of wild strain.

\subsubsection{Response Surface Methodology for Ergot Alkaloids Synthesis}

In response surface methodology, statistical models such as Plackett-Burman and Box-Behnken designs were used for the statistical optimization of fermentation ingredients/variables for enhancing the yield of ergot alkaloids [14,38].

\subsection{Preparation of Inoculum}

Spore suspension of PCUV-4 (best mutant among all UV and EMS treated strains) was prepared by scratching the surface of its colonies and mixing the fungal spores in flask containing $50 \mathrm{~mL}$ of distilled water. The number of spores was adjusted at $10^{6-7}$ spores/mL using hemocytometer. 


\subsection{Response Surface Methodology}

\subsubsection{Plackett-Burman design (PBD) for Screening of Fermentation Factors}

The Plackett-Burman design (PBD) was used for the screening of fermentation factors (ingredients) which were used to get the highest yield of ergot alkaloids. In this step, " $x$ " variables were screened by formulating " $x+1$ " fermentation factor [11]. The fermentation factors used in this step were yeast Extract, Succinic acid, Sucrose, Tryptophan, Asparagine, $\mathrm{MgSO}_{4} .7 \mathrm{H}_{2} \mathrm{O}, \mathrm{FeSO}_{4}, \mathrm{ZnSO}_{4}, \mathrm{KH}_{2} \mathrm{PO}_{4}$ and $\mathrm{pH}$. First, a numerical factor was given to all the fermentation factors and second, all of these factors were investigated at two different levels such as -1 (low level) and +1 (high level) for the production of ergot alkaloids. The experimental range, levels and design are presented in Tables 9 and 10.

Table 9. Plackett-Burman design (PBD) range and level for screening of factors.

\begin{tabular}{|c|c|c|}
\hline \multicolumn{2}{|c|}{ Range and Level } & \multirow{2}{*}{ Fermentation Factor } \\
\hline-1 & +1 & \\
\hline 5 & 35 & Sucrose, X1 \\
\hline 5 & 30 & yeast Extract, X2 \\
\hline 0.1 & 1 & Succinic acid, X3 \\
\hline 0.1 & 1 & Asparagine, $\mathrm{X} 4$ \\
\hline 0.1 & 1 & Tryptophan, X5 \\
\hline 0.1 & 1 & $\mathrm{KH}_{2} \mathrm{PO}_{4}, \mathrm{X} 6$ \\
\hline 0.25 & 0.625 & $\mathrm{MgSO}_{4}, \mathrm{X7}$ \\
\hline 0.01 & 0.1 & $\mathrm{FeSO}_{4}, \mathrm{X} 8$ \\
\hline 0.02 & 0.2 & $\mathrm{ZnSO}_{4}, \mathrm{X9}$ \\
\hline 3 & 5 & $\mathrm{pH}, \times 10$ \\
\hline
\end{tabular}

$\mathrm{X} 1, \mathrm{X} 2 \ldots \ldots \mathrm{X} 10$ are fermentation factors.

Table 10. PBD experimental design for screening of factors.

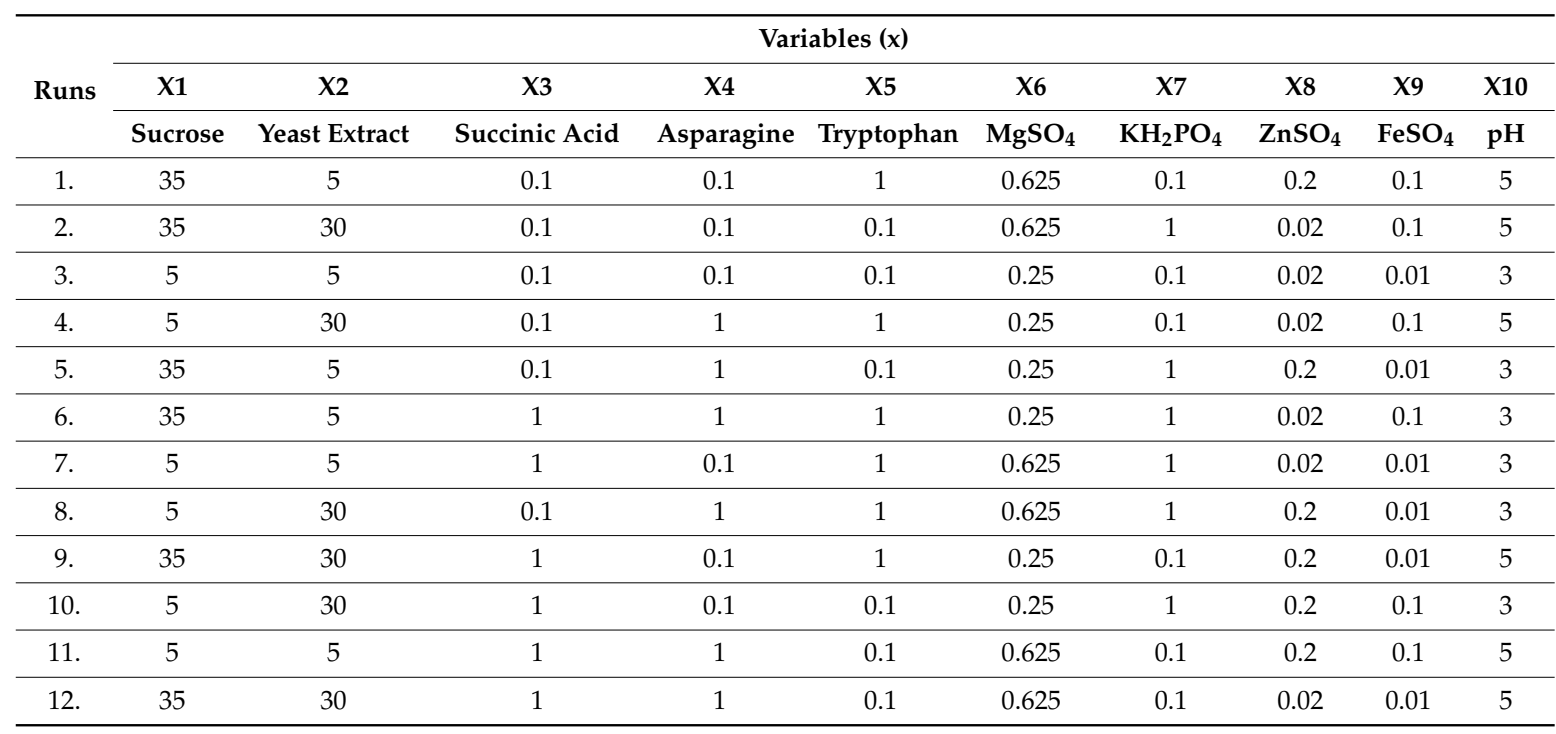

$\mathrm{X} 1, \mathrm{X} 2 \ldots \ldots \mathrm{X} 10$ are fermentation factors/variables. 
The twelve (12) experimental runs were designed as mentioned in Table 10 after Plackett and Burman (1946) [11]. For all of the experiments, three replicates were developed and the average yield (response) of these replicates was measured. The impact of fermentation factors on the yield of ergot alkaloids was measured by formulating the following equation:

$$
Y=\beta_{\mathrm{O}}+\sum \beta_{X_{i}}
$$

where, ' $Y$ ' is the yield or response, ' $\beta_{0}$ ' is the intercept, ' $\beta_{X_{i}}$ ' is the linear coefficient (fermentation factor). The $0.1-\mathrm{N} \mathrm{HCl}$ and ammonia solution were used to maintain the $\mathrm{pH}$ for all runs designed in PBD. All of these flasks were autoclaved at $121^{\circ} \mathrm{C}, 15 \mathrm{lb} / \mathrm{inch}^{2}$ for $15 \mathrm{~min}$ and after inoculation flasks were incubated at $25^{\circ} \mathrm{C}$ for 21 days.

\subsubsection{Identification of Significant Factors Using Box-Behnken Design (BBD)}

After screening using PBD model, BBD was employed to find out the most crucial fermentation factors for the production of alkaloids. Here, further optimization of significant fermentation factors and impact of their mutual interaction on the production of ergot alkaloids was observed. This step was done after [12]. In this step, 13 runs were designed, and the significant fermentation factors were studied at three different levels such as low (-1), medium $(0)$ and high $(+1)$. The BBD range and levels are presented in Table 11. All the experiments were done in triplicate and the average of ergot alkaloids yield was considered as the response $(\mathrm{Y})$. The following polynomial equation was formulated to identify the $Y$ as response:

$$
Y=\beta_{\mathrm{o}}+\sum \beta_{\mathrm{ii}}+X \sum \beta_{\mathrm{ii}} \mathrm{x} \mathrm{i}^{2}+\sum \beta_{\mathrm{ij}} \mathrm{X}_{\mathrm{i}} \mathrm{X}_{\mathrm{j}}
$$

Table 11. BBD experimental levels.

\begin{tabular}{cccc}
\hline \multicolumn{3}{c}{ Level and Range } & Fermentation Factor \\
\cline { 1 - 3 } $\mathbf{- 1}$ & $\mathbf{0}$ & $\mathbf{+ 1}$ & \\
\hline 5 & 23 & 41 & Sucrose, $\mathrm{X} 1$ \\
\hline 5 & 22 & 39 & yeast Extract, $\mathrm{X} 2$ \\
\hline 0.01 & 0.06 & 0.11 & $\mathrm{FeSO}_{4}, \mathrm{X} 3$ \\
\hline
\end{tabular}

In this ' $Y^{\prime}$ is the predicted response, ' $\mathrm{XiXj}$ ' is the input variables which influence ' $Y^{\prime} ;$ ' $\beta_{\mathrm{o}}$ ' intercept coefficient, ' $\beta_{\mathrm{ii}}$ ' linear coefficient; ' $\beta_{\mathrm{ii}} \times \mathrm{i}^{2 \prime}$ quadratic coefficient and ' $\beta_{\mathrm{ij}}$ ' interaction of these variables. 'X1, X2 and $\mathrm{X}^{\prime}$ ' are fermentation factors. The experimental design of BBD is presented in Table 12. The $\mathrm{pH}$ of all runs was maintained at 5.0 using $0.1-\mathrm{N} \mathrm{HCl}$ and ammonia solution. The media was autoclaved at $121^{\circ} \mathrm{C}$ for $15 \mathrm{~min}$ under $15 \mathrm{lb} /$ inch $^{2}$ and after inoculation, all flasks were incubated at $25{ }^{\circ} \mathrm{C}$ for 21 days.

Table 12. BBD experimental design for optimization of fermentation factors.

\begin{tabular}{cccc}
\hline \multirow{2}{*}{ Runs } & \multicolumn{3}{c}{ Variables } \\
\cline { 2 - 4 } & $\mathbf{X 1}$ & $\mathbf{X 2}$ & $\mathbf{X 3}$ \\
\cline { 2 - 4 } & Sucrose & Yeast Extract & FeSO $_{4}$ \\
\hline 1 & 41 & 5 & 0.06 \\
\hline 2 & 41 & 39 & 0.06 \\
\hline 3 & 41 & 22 & 0.01 \\
\hline 4 & 41 & 22 & 0.11 \\
\hline 5 & 5 & 5 & 0.06 \\
\hline
\end{tabular}


Table 12. Cont.

\begin{tabular}{cccc}
\hline \multirow{2}{*}{ Runs } & \multicolumn{3}{c}{ Variables } \\
\cline { 2 - 4 } & $\mathbf{X 1}$ & $\mathbf{X 2}$ & $\mathbf{X 3}$ \\
\hline & Sucrose & Yeast Extract & FeSO $_{4}$ \\
\hline 6 & 5 & 39 & 0.06 \\
\hline 7 & 5 & 22 & 0.01 \\
\hline 8 & 5 & 22 & 0.11 \\
\hline 9 & 23 & 5 & 0.01 \\
\hline 10 & 23 & 39 & 0.01 \\
\hline 11 & 23 & 5 & 0.11 \\
\hline 12 & 23 & 39 & 0.11 \\
\hline 13 & 23 & 22 & 0.06 \\
\hline
\end{tabular}

\subsubsection{Statistical Analyses of RSM}

The STATISTICA version 7 (Stat-Ease, Inc., Minneapolis, MN, USA) software was used for statistical analysis and also for developing 3D figures of response surface methodology.

\subsection{Ergot Alkaloids Determination}

After 21 days of incubation the fermented broth was processed and intracellular mass (fungal mycelium) was separated from extracellular liquid (supernatant). The mycelial mass and fermented broth was stored at $4{ }^{\circ} \mathrm{C}$ for further analysis.

\subsubsection{Ergot Alkaloids in Fermented Broth Extract}

The separated fermented broth was centrifuged at 10,000 rpm/min for $10 \mathrm{~min}$ at $4{ }^{\circ} \mathrm{C}$ and the extract (supernatant) was collected in a separate glass bottle. The extract was purified using rotary evaporator [39]. After purification, $1 \mathrm{~mL}$ of purified extract was taken in a test tube and $2 \mathrm{~mL}$ of Van Urk reagent was added in it. The reaction mixture was incubated at $37^{\circ} \mathrm{C}$ for $30 \mathrm{~min}$ in water bath. The optical density (OD) was measured using Spectrophotometer (Hitachi U2900/U2910 double beam) at $590 \mathrm{~nm}$.

\subsubsection{Ergot Alkaloids in Extract of Mycelia}

The mycelia were placed in oven for drying at $40^{\circ} \mathrm{C}$ for $24 \mathrm{~h}$ after measuring their initial weights. After $24 \mathrm{~h}$, dried mycelia were soaked in chloroform for $3 \mathrm{~h}$. All the soaked mycelia were crushed and grinded by sonication process at $200 \mathrm{rpm} / \mathrm{min}$ for $15 \mathrm{~min}$ using Ultrasonic Generator. The paste was homogenized in a homogenizer for 15 minutes. The homogenized pastes were then centrifuged at $10,000 \mathrm{rpm}$ at $4{ }^{\circ} \mathrm{C}$ for $10 \mathrm{~min}$. The extract of mycelia was purified using rotary evaporator. The purified extract was assayed using Van Urk reagent and measured at $590 \mathrm{~nm}$ in Spectrophotometer (Hitachi U2900/U2910 double beam).

Author Contributions: M.G.S. is the main author of the research study. This is a part of my PhD research thesis. Therefore, the main conceptualization, methodology, research experimentations, interpretations and original draft preparations were done by me. M.N. is the supervisor of my thesis and the major contribution is done by him in designing and determination of the protocols. A.G. did the formal analysis and contributed in writing (review and editing), M.S. done validation and helped in writing (review and editing), H.u.R. helped in the visualization, computing resources and editing of drfat specially the statistical analysis. G.Z.G.; M.U.H.; L.S.; and R.A. contributed in writing (review and editing). R.N. helped in the formal analysis of PBD and BBD. All authors have read and agreed to the published version of the manuscript.

Funding: No outside funding was provided for this research. 
Acknowledgments: The authors acknowledge the Pakistan Council of Scientific and Industrial Research, Lahore, Pakistan and the Department of Botany, GC University, Lahore for providing the technical facilities for the smooth conduction of all the experiments of the study.

Conflicts of Interest: There were no conflicts of interest during the research studies.

\section{References}

1. Pichersky, E.; Gang, D.R. Genetics and biochemistry of secondary metabolites in plants: An evolutionary perspective. Trends Plant Sci. 2000, 5, 439-445. [CrossRef]

2. Shahid, M.G.; Nadeem, M.; Baig, S.; Cheema, T.A.; Atta, S.; Ghafoor, G. Screening and optimization of some inorganic salts for the production of ergot alkaloids from Penicillium species using surface culture fermentation process. Pak. J. Pharma. Sci. 2016, 29, 407-414.

3. Shahid, M.G.; Baig, S.; Nadeem, M.; Cheema, T.A.; Nelofar, R.; Saleem, M. Biosynthesis of ergot alkaloids from Penicillium commune using response surface methodology (RSM). Pak. J. Bot. 2017, 49, 1569-1578.

4. Zafar, A.M.; Waseemuddin, S.A.; Azhar, I.; Sualeh, M.; Baig, M.T.; Zoha, S.M.S. Bioactive alkaloids produced by fungi: Updates on alkaloids from the species of the genera Boletus, Fusarium and Psilocybe (Review). Pak. J. Pharma. Sci. 2010, 23, 349-357.

5. Gulliamon, J.M.; Sabate, J.; Barrio, E.; Cano, J.; Querol, A. Rapid identification of nine Yeast species based on RFLP analysis of ribosomal internal transcribed spacer (ITS) regions. Arch. Microbiol. 1998, 169, 387-392.

6. Tiwari, K.L.; Jadhav, S.K.; Fatima, A. Culture conditions for the production of thermostable amylase by Penicillium rugulosum. Glob. J. Biotechnol. Biochem. 2007, 2, 21-24.

7. Kozlovsky, A.G.; Zhelifonova, V.P.; Antipova, T.V. Biologically active metabolites of Penicillium fungi. Org. Biomol. Chem. 2013, 1, 11-21.

8. Nina, G.; Neubauer, L.; Tudzynski, P.; Shu-Ming, L. Biosynthesis pathways of ergot alkaloids. Toxins 2014, 6, 3281-3295.

9. Khurana, S.; Kapoor, M.; Gupta, S.; Kuhad, R.C. Statistical optimization of alkaline xylanase production from Streptomyces violaceoruber under submerged fermentation using response surface methodology. Ind. J. Microbiol. 2007, 47, 144-152. [CrossRef]

10. Trejo, H.M.R.; Lonsane, B.K.; Raimbault, M.; Roussost, S. Spectra of ergot alkaloids produced by Claviceps purpurea $1029 \mathrm{c}$ in solid-state fermentation system: Influence of the composition of liquid medium used for impregnating sugar-cane pith bagasse. Proc. Biochem. 1993, 28, 23-27. [CrossRef]

11. Plackett, R.L.; Burman, J.P. The design of optimum multifactorial experiments. Biometrika 1946, 33, 305-325. [CrossRef]

12. Box, G.E.P.; Behnken, D.W. Some new three level designs for the study of quantitative variables. Technometrics 1960, 2, 455-475. [CrossRef]

13. Naveena, B.J.; Altaf, M.D.; Bhadriah, K. Selection of medium components by Plackett-Burman design for production of L (+) lactic acid by Lactobacillus amylophilus GV6 in SSF using wheatbran. Bioresour. Technol. 2005, 96, 485-490. [CrossRef]

14. Venil, C.K.; Lakshmanaperumalsamy, P. Application of statistical design to the optimization of culture medium for prodigiosin production by Serratia marcescens SWML08. Malays. J. Microbiol. 2009, 5, 55-61.

15. Shahid, M.G.; Baig, S.; Saleem, M.; Arif, R.; Ghafoor, G.; Liaqat, A. Qualitative and quantitative analysis of ergot alkaloids produced by Aspergillus niger through surface culture fermentation process. Pak. J. Bot. 2018, 50, 2423-2428.

16. Devi, N.N.; Prabakaran, J.J. Bioactive metabolites from an endophytic fungus Penicillium sp. isolated from Centella asiatica. Curr. Res. Environ. Appl. Mycol. 2014, 4, 34-43. [CrossRef]

17. Roberts, M.R.; Wink, M. Alkaloids: Biochemistry, Ecology and Medical Applications; Plenum: New York, NY, USA, 1998; pp. 135-146.

18. Onyegeme-Okerenta, B.M.; Okochi, V.I.; Chinedu, S.N. Penicillin production by Penicillium chrysogenum PCL 501: Effect of UV induced mutation. Int. J. Microbiol. 2013, 12, 1-10.

19. Veerapagu, M.; Jeya, K.R.; Ponmurugan, K. Mutational Effect of Penicillium chrysogenum on Antibiotic Production; Advanced Biotech: Totowa, NJ, USA, 2008; pp. 16-19.

20. Moussa, L.A.A. Effect of some factor including irradiation on the ergot alkaloids production by members of Penicillium. J. Biol. Res. 2003, 3, 65-81. 
21. El-Bondkly, A.M.; Abeer, A.K. UV- and EMS- induced mutations affecting synthesis of alkaloids and lipase in Penicillium roquefortii. Arab. J. Biotechnol. 2007, 10, 241-248.

22. Hamad, A.; Haq, I.; Qadeer, M.A.; Javed, I. Screening of Bacillus licheniformis mutants for improved production of alpha-amylase. Pak. J. Bot. 2001, 33, 517-525.

23. Nadeem, M. Biotechnological Production of Alkaline Protease for Industrial Use. Ph.D. Thesis, Department of Zoology, University of the Punjab, New Campus, Lahore, Pakistan, 2009.

24. Rao, J.M.; Kim, C.; Rhee, S. Statistical optimization of medium for the production of recombinant hirudin from Sacchromyces cerevisiae using response surface methodology. Proc. Biochem. 2000, 35, 639-647. [CrossRef]

25. Venil, C.K.; Lakshmanaperumalsamy, P. Applications of response surface methodology in medium optimization for protease production by the new strain of Serratia marcescens SWML08. Pol. J. Microbiol. 2009, 58, 117-124.

26. Mao, X.B.; Eksriwong, T.; Chauvatcharin, S.; Zhong, J.J. Optimization of carbon source and carbon/nitrogen ratio for cordycepin production by submerged cultivation of medicinal mushroom Cordyceps militaris. Proc. Biochem. 2005, 40, 1667-1672. [CrossRef]

27. Wu, Q.; Yong-Chun, S.; Xu, H.; Guo, Y.; Li, J.; Ren-Xiang, T. Medium optimization for enhanced co-production of two bioactive metabolites in the same fermentation by a statistical approach. J. Asian Nat. Prod. Res. 2011, 13, 1110-1121.

28. Rubina, N.; Ramnan, R.N.; Rahman, R.N.Z.R.; Basri, M.; Ariff, A.B. Sequential optimization of production of a thermostable and organic solvent tolerant lipase by recombinant Escherichia coli. Ann. Microbiol. 2011, 61, 535-544.

29. Liu, Y.; Wang, F.; Tan, T. Cyclic resolution of racemic ibuprofen via coupled efficient lipase and acid base catalysis. Chirality 2009, 21, 349-353. [CrossRef]

30. Pan, H.; Xie, Z.; Bao, W.; Zhang, J. Optimization of culture conditions to enhance cis-epoxysuccinate hydrolase production in Escherichia coli by response surface methodology. Biochem. Eng. J. 2008, 42, 133-138. [CrossRef]

31. Lee, D.W.; Koh, Y.S.; Kim, B.C.; Choi, H.J.; Kim, D.S.; Suhartono, M.T.; Pyun, Y.R. Isolation and characterization of thermophilic lipase from Bcillus thermoleovorans ID-1. FEMS Microbiol. Lett. 1999, 179, 393-400. [CrossRef]

32. Wang, X.L.; Liu, G.Q. Preliminary select and optimization of submerged fermentation media of Ganoderma sinense. Food Sci. Technol. 2009, 34, 14-16.

33. Krishnaa, D.; Krishnaa, K.S.; Padma, S.R. Response surface modeling and optimization of chromium (Vi) removal from aqueous solution using Borasus flabellifer coir powder. Int. J. Appl. Sci. Eng. 2013, 11, 213-226.

34. Amara, A.A.F. Optimizing PHB and protease production by Box-Behnken design. J. IILUM Eng. 2013, 14, 15-28. [CrossRef]

35. Yasin, S.; Curti, M.; Behary, N.; Perwuelz, A.; Giraud, S.; Rovero, G.; Guan, J.; Chen, G. Process optimization of eco-friendly flame retardant finish for cotton fabric: A response surface methodology approach. Surf. Rev. Lett. 2017, 24, 1750114. [CrossRef]

36. Cheng, S.W.; Wang, Y.F.; Hong, B. Statistical optimization of mediumcompositions for chitosanaseproduction by a newly isolated Streptomyces albus. Braz. J. Chem. Eng. 2012, 29, 691-698. [CrossRef]

37. Sreedevi, K.; Venkateswara, R.J.; Lakshmi, N.; Fareedullah, M. Strain improvement of Aspergillus terreus for the enhanced production of lovastatin, a HMG-COA reductase inhibitor. J. Microbiol. Biotechnol. Res. 2011, 1, 96-100.

38. Ryan, K.L.; Christopher, T.M.; Panaccione, D.G. Partial reconstruction of the ergot alkaloid pathway by heterologous gene expression in Aspergillus nidulans. Toxins 2013, 5, 445-455. [CrossRef]

39. Naude, T.W.; Botha, C.J.; Vorster, J.H.; Roux, C.; Van der linde, E.J.; Van der walt, S.L.; Rottinghaus, G.E.; Van jaarsveld, I.; Lawrence, A.N. Claviceps cyperi, a new cause of severe ergotism in dairy cattle consuming maize silage and teff hay contaminated with ergotised Cyperus esculentus (nut sedge) on the Highveld of South Africa. Onderstepoort J. Vet. Res. 2005, 72, 23-37. [CrossRef]

(C) 2020 by the authors. Licensee MDPI, Basel, Switzerland. This article is an open access article distributed under the terms and conditions of the Creative Commons Attribution (CC BY) license (http://creativecommons.org/licenses/by/4.0/). 